\title{
Desafios da Pastoral Familiar para a vida plena e a comunhão missionária
}

Recebido: 24/02/2016. Aprovado: 02/03/2016.

\author{
João Carlos (Giancarlo) Petrini*
}

Resumo: O autor faz uma séria análise crítica dos grandes desafios que a família enfrenta nos tempos atuais. Alguns dependem da organização das sociedades modernas. Outras são de caráter antropológico e dependem das mudanças culturais, éticas e religiosas que estão acontecendo. Essas mudanças colocam em questão valores e horizontes de realização humana que orientaram durante milênios a conduta de homens e de mulheres em busca da felicidade, mas também produzem sofrimentos e feridas abertas em muitas pessoas. Discute-se hoje: o que significa ser homem, ser mulher e por que não decidir o próprio gênero de modo autônomo e livre de condicionamentos biológicos e sociais? Não será melhor desfazer todos os vínculos que nos amarram, impedindo que sejamos livres para novas formas de realização que poderão aparecer no horizonte? É mesmo verdade que que a maternidade e a paternidade são essenciais à realização humana de uma pessoa adulta? Ou, antes, não será isto uma imposição da cultura originada no passado e da qual hoje nós podemos nos libertar? Diante dessas perguntas, aumenta o número dos que manifestam certezas que nascem não da experiência e, sim, de construções ideológicas. Nesse contexto, reconhece-se a importância a ser dada aos ensinamentos cristãos a respeito do matrimônio e da família.

Palavras-chave: Família e mudanças; Desafios culturais; Consolidação da família.

Abstract: The author analyses very critically the big challenges the family has to cope with in the present times. Some result from the organization of modern societies. Other are of an anthropological character and depend on the cultural, ethical and religious changes that are going on. These changes defy values and horizons that for millennia guided the behavior of men and women in their looking for happiness, but also do cause sufferings and open wounds in many people. Today people question what does it mean to be a man, to be a woman, and why not to decide one's gender autonomously and without biological and social conditionings? Wouldn't be it better to undo all the bonds that tie us, preventing us to be free to test new forms of realization that could appear? Is it really true that maternity and paternity are essential to the human realization of and adult person?

Or, on the contrary, wouldn't it be an imposition by a culture from the past and from which we could free us? Before these questions, grows the number of people who show certainties that are born not from experience but, on the contrary, from ideological constructions. In this context, one acknowledges the importance to be given to the Christian teachings about marriage and family.

Key-words: Family and changes; cultural challenges; consolidation of the family.

* Doutor em Ciências Sociais pela PUC-SP, São Paulo, SP (1992). Professor do Programa de Pós-Graduação em Família na Sociedade Contemporânea, da Universidade Católica do Salvador, Salvador, BA. Diretor da seção brasileira do Pontifício Instituto João Paulo II para Estudos sobre Matrimônio e Família. Membro da Comissão Episcopal Pastoral para a Vida e a Vida e a Família, da CNBB. Bispo de Camaçari, BA. 


\section{Introdução}

Estamos vivendo uma etapa da Igreja profundamente marcada pela figura do Papa Francisco. Ele identificou a família como uma realidade que merece uma atenção especial. De fato, dois sínodos foram dedicados à família, o extraordinário de 2014 e o ordinário de $2015 .{ }^{1}$

Uma nota dominante nos ensinamentos do Papa Francisco é o convite a "curar as feridas e aquecer os corações dos fiéis". Afirma o Papa: "As pessoas têm de ser acompanhadas, as feridas têm de ser curadas. [...] Os ministros do Evangelho devem ser capazes de aquecer o coração das pessoas, de caminhar na noite com elas, de saber dialogar e mesmo de descer às suas noites, na sua escuridão, sem perder-se". E noutra passagem disse: "Vejo a Igreja como um hospital de campanha depois de uma batalha [...], pois muitos vivem feridas abertas". ${ }^{2}$

O Papa quer dirigir este olhar de compaixão a todas as realidades onde as feridas estão abertas. É o olhar que move seus passos de pastor. É o olhar que ele pede a todos os batizados: que cada um seja missionário, portador de uma compaixão semelhante à de Jesus Cristo. De fato, outra nota dominante no ensinamento do Papa Francisco é a centralidade de Jesus Cristo, em sintonia con o Documento de Aparecida.

A família enfrenta grandes desafios. Alguns dependem da organização das sociedades modernas. Outras são de caráter antropológico e dependem das mudanças culturais, éticas e religiosas que estão acontecendo. Essas mudanças colocam em questão valores e horizontes de realização humana que orientaram durante milênios a conduta de homens e de mulheres em busca da felicidade, mas também produzem sofrimentos e feridas abertas em muitas pessoas. ${ }^{3}$

Atualmente não mais se discute a possibilidade de usar a pílula ou de divorciar-se, como acontecia nos anos 60 e 70. Discute-se: o que significa ser homem, ser mulher e por que não decidir o próprio gênero de modo autônomo e livre de condicionamentos biológicos e sociais? Não será melhor desfazer todos os vínculos que nos amarram, impedindo que sejamos livres para novas formas de realização que poderão aparecer no horizonte? É mesmo verdade que que a maternidade e a paternidade são essenciais à realização humana

\footnotetext{
DAp. 432-437.

2 La Civiltà Cattolica. Entrevista ao Papa Francisco, agosto 2013.

3 DAp. 33-82, especilmente o n. 44.
} 
de uma pessoa adulta? Ou, antes, não será isto uma imposição da cultura originada no passado e da qual hoje nós podemos nos libertar? Diante dessas perguntas, aumenta o número dos que manifestam certezas que nascem não da experiência e, sim, de construções ideológicas.

\section{A familia é tudo ou é nada?}

Uma sondagem de opinião, realizada em 2007 por um prestigioso instituto brasileiro, ${ }^{4}$ revelou que $98 \%$ das pessoas entrevistadas consideram a família importante ou muito importante. Parece incrível que a família goze de tanta aceitação. Além disso, a família foi escolhida pelo governo brasileiro como parceira para realizar políticas de combate à pobreza e à evasão escolar. Alguém poderia afirmar: nunca a família foi tão valorizada como nestes últimos tempos.

Por outro lado, programas apresentados pelos meios de comunicação e decisões tomadas pelos poderes da república (judiciário, legislativo, executivo) consideram família qualquer convivência debaixo do mesmo teto, sem outras especificações além da existência de algum tipo de afetividade que ligue aquelas pessoas entre si.

Nesse sentido, alguém poderia ponderar: nunca a família foi considerada de maneira tão fluida, com contornos tão indefinidos e sua identidade diluída a ponto de poder desaparecer como grupo socialinstituição com características próprias bem delineadas.

Esta situação paradoxal segundo a qual ora a família é tudo, ora é nada, ${ }^{5}$ documenta quão profundo é o processo de mudança que envolve a sociedade brasileira em todas as suas dimensões e revela a pluralidade de posturas, e a diversidade de valores e metas que se encontram em nossa cultura. ${ }^{6}$

\section{O entrelaçamento de amor, sexualidade e fecundidade}

Um fato especialmente significativo influencia e desarticula a família a partir do final dos anos 50 do século passado: a ruptura do entrelaçamento de amor, sexualidade e procriação. ${ }^{7}$

4 FOLHA DE SÃO PAULO. Família brasileira: Retrato falado. Pesquisa nacional do Datafolha, 7 de outubro de 2007.

5 COOPER, David. A morte da família. São Paulo: Martins Fontes. 1994.

6 KALOUSTIAN, S.M. (Org.). Família brasileira, a base de tudo. São Paulo: Cortez, 1994.

7 A este respeito, veja-se também Instrumentum laboris, n. 26. 
Desde as origens até o final dos anos 50, amor, sexualidade e procriação estavam profundamente unidos, num entrelaçamento poderoso que constituiu o núcleo do matrimônio e da família. Nesse horizonte, o amor, isto é, o dom de si para o bem do outro, exprime-se e encontra a sua plenitude humana na intimidade sexual e está aberto para a procriação, criando um vínculo entre os cônjuges e responsabilidade para com os filhos. ${ }^{8}$

Atualmente, a dimensão lúdica parece esgotar o significado da sexualidade humana que pode ser vivida sem abertura para a fecundidade e sem amor, não encontrando mais limites, podendo-se eliminar dela qualquer responsabilidade ou vínculo que estenda seus efeitos para além do momento em que se realiza como jogo. Nestas últimas décadas, esse entrelaçamento e o vínculo que gera parecem dispensáveis e a sexualidade torna-se um lazer sem consequências ${ }^{9}$.

De forma análoga, a fecundidade separada do exercício da sexualidade e do amor aproxima-se da atividade produtiva, segundo a lógica do mercado capitalista, incluindo a avaliação de custos e benefícios, discutindo-se as prestações a pagar e o prazo de entrega. Nesse ambiente, é fácil que o amor seja vivido como sentimento efêmero ou paixão que não gera vínculos duradouros. A fecundidade desligada de uma relação de amor aparece agora como definida pela decisão individual e pelo acesso à tecnologia sofisticada ${ }^{10}$.

\section{Redução da cooperação entre sexos e entre gerações}

Diversos fatores convergem para enfraquecer a cooperação entre os sexos (os gêneros) e entre as gerações. Tal cooperação constitui a característica essencial das mais distintas formas de família. Um grupo de pessoas é reconhecido como família quando se configura como uma relação de plena reciprocidade entre os sexos e entre as gerações ${ }^{11}$.

8 MELINA, L. Corso di bioetica. Casale Monferrato: PIEMME, 1996; SCOLA, A. I/ mistero nuziale, op. cit. A este respeito, veja-se também Instrumentum laboris, n. 122.

9 CAFFARRA, C. Ética generale della sessualità. Milão: Ares, 1992.

10 OLIVEIRA, M.A. Ética e racionalidade moderna. 2.ed. São Paulo: Loyola, 1993; RHONHEIMER, M. Ética della procreazione. Roma: Mursia, 2000; AZEVEDO, E.E.S. O direito de vir a ser após o nascimento. Porto Alegre: EDIPUCRS, 2000; SEGRE, M.; COHEN, C. Bioética. Rio de Janeiro: Civilização Brasileira, 2000.

11 DONATI, Manuale di sociologia della famiglia. Bari: Laterza, 1998; BRONFENBRENNER, U. A ecologia do desenvolvimento humano: experimentos naturais e planejados. 
Formas de cooperação entre os cônjuges e destes com eventuais filhos e com os velhos pais podem ser encontradas em todos os modelos de família, ao longo da história e nas diferentes culturas. Uma sociedade será tanto mais civilizada, solidária e capaz de viver em paz quanto maior for essa cooperação.

No entanto, na sociedade contemporânea, é justamente esta cooperação que entra em crise, dando lugar a conflitos e disputas. A família passa, então, a ser considerada como um interesse menor, ampliando-se a disponibilidade a quebrar os vínculos familiares entre cônjuges, ${ }^{12}$ bem como entre pais e filhos, quando são percebidos como limitadores da própria expressividade. Difunde-se uma imagem de vida adulta "livre" da convivência familiar, reforçando a tendência que considera dispensável o vínculo familiar.

\section{A família no contexto político}

A esfera pública, desde os anos 50, era dominada por uma mentalidade que enxergava somente indivíduos: o trabalhador, o desempregado, a criança, a mulher, o negro, o adolescente, o idoso, como se eles existissem fora de uma concreta rede de relações familiares. As relações familiares eram consideradas irrelevantes aos fins da organização social e à defesa dos direitos da cidadania. Em muitos casos, a família era considerada não somente irrelevante, mas perniciosa, como o adversário político que deveria ser derrotado para que modos de agir mais afinados com o processo de modernização pudessem encontrar terreno favorável à sua expansão.

Não deixa de ser curiosa a convergência de forças políticas e ideológicas muito diferentes entre si, na maneira de avaliar a família como, por exemplo, o desenvolvimentismo, o marxismo, a psicanálise. A família tradicional, compreendida através dos esquemas do modelo patriarcal, representava exatamente o que devia ser superado e deixado para trás. A família era considerada como o lugar da reprodução de uma mentalidade conservadora, contrária à revolução, à militância política ou às inovações culturais.

Porto Alegre: Artes Médicas, 1996.

12 A este respeito, veja-se Instrumentum laboris, n. 65. 
Era acalentada a possibilidade de remodelar o homem e a história de acordo com projetos utópicos, desconsiderando o legado do passado para dedicar-se a uma construção nova desde a raiz. Esse entusiasmo pelas possibilidades inéditas de construção de um mundo novo e de um ser humano novo era alimentado pelo mito da revolução ${ }^{13}$ que desde a tomada da Bastilha não tinha parado de se expandir, adquirindo novos impulsos depois da revolução cubana e nicaraguense, mas também novos significados, com a substituição dos antigos ideais políticos com objetivos de emancipação individual e liberação subjetiva.

\section{Desconstrução do passado, evaporação do futuro: a implosão do tempo}

No início da modernidade, o passado tinha sido desvalorizado, considerado como o tempo da tutela de autoridades externas14 (a Bíblia ou o Papa) percebidas como contrárias à razão e à liberdade, época das superstições, rejeitado como concentração de erros que finalmente seriam superados no futuro próximo.

O centro de gravidade da cultura deslocou-se do passado para o futuro, isto é, para a experimentação, que inaugura o novo. Motivo da esperança não era mais a memória dos fatos passados, dos heróis e dos santos, como arquétipos fundadores de nacionalidades e modelos de civilização, mas o futuro, as realizações que a razão técnica e científica poderia proporcionar. $\mathrm{O}$ ideal das classes dirigentes era deixar para trás o peso do passado, lançando-se nas promessas do futuro.

No entanto, a perspectiva otimista desenvolvida no século XIX decaiu rapidamente quando grandes eventos de destruição e morte constituíram sinais de alerta a respeito da crise da modernidade: duas guerras mundiais, os totalitarismos nazistas e estalinistas, as bombas atômicas, a realidade da fome, o desastre ecológico, a expansão das drogas, a ciência aplicada à produção de armas. O futuro luminoso, que tinha sido anunciado como certo, começou a receber sérias críticas.

13 DUMONT, Jean. I falsi miti della rivoluzione francese. Milão: EdF, 1989; FURET, François e RICHET, Denis. La rivoluzione francese. Bari: Laterza, 1980.

14 Lembramos a resposta de Kant à pergunta: "O que é iluminismo?": A saída da menoridade...". 


\section{A desconstrução do futuro}

As construções utópicas que pretendiam acelerar o advento do futuro, passaram a ser desconstruídas, como fábulas sem fundamento na realidade. Discursando no Conseil des Universités de Québec, a respeito da situação do conhecimento em época de alta tecnologia nas sociedades avançadas, Lyotard chamou os grandes ideais que se originaram no Iluminismo de "metanarrativas", isto é, fábulas, afirmando que elas são destituídas de credibilidade. "Simplificando ao extremo, eu defino o pós-moderno como incredulidade com relação às metanarrativas". ${ }^{15} \mathrm{Na}$ primeira etapa da modernidade havia sido desconstruído o passado, agora era o futuro a perder validade. As promessas utópicas dos mais variados tipos que adiavam para o futuro o tempo da realização perderam credibilidade.

\section{A primazia do aqui e agora}

As possibilidades de satisfação passaram a concentrar-se no tempo presente. "Às visões entusiásticas do progresso histórico sucediam-se horizontes mais curtos, uma temporalidade dominada pelo precário e pelo efêmero [...] marcada pela primazia do aqui e agora" ${ }^{16} \mathrm{O}$ mercado passa a ser fonte de satisfação. Nele concentram-se, agora, as esperanças de realização individual.

Com a derrocada das construções voluntaristas do futuro e com o triunfo dos modelos consumistas concentrados no presente, inaugura-se um tempo separado de suas origens e de seu destino. Homens e mulheres sem raízes e sem metas, a não ser a fruição dos bens que a modernidade estava oferecendo, numa nova edição do carpe diem. ${ }^{17}$ Não faltaram alertas para os problemas de uma cultura que corta suas raízes. ${ }^{18}$

5 LYOTARD, Jean François. The Posmodern Condition: a report on Knowledge. Minneapolis: University of Minnesota Press, 1984, p. 99-100.

16 LIPOVETSKY, Gilles; CHARLES Sebastien. Os tempos hipermodernos. São Paulo: Barcarolla, 2004, p. 51

17 LIPOVETSKY, Gilles. Metamorfose da cultura liberal. Ética, mídia, empresa. Porto Alegre: Sulina, 2004, p. 51. Veja-se também Instrumentum laboris, n. 22.

18 WEIL, Simone. O enraizamento. Bauru: EDUSC, 2001; e BOSI, Ecléa. Cultura de massa e cultura popular. Leituras operárias. Petrópolis: Vozes, 1977. 
Sem história da qual orgulhar-se e sem futuro capaz de mobilizar as energias em vista de um projeto pessoal e social, sobram, especialmente para as novas gerações, satisfações efêmeras e emoções momentâneas. Nesse cenário, apareceu um indivíduo instável, de convicções voláteis e compromissos fluidos. A cultura do efêmero ${ }^{19}$ faz perceber os vínculos familiares mais como amarras que limitam do que como recursos essenciais para a própria realização humana. ${ }^{20}$

\section{O mercado coloniza o mundo da vida}

O mercado tornou-se um poder impessoal capaz de condicionar os próprios Estados. Estes, com efeito, devem adaptar seus programas de desenvolvimento e suas políticas econômicas ao seu comportamento. $\mathrm{O}$ "nervosismo" do mercado torna-se motivo de apreensão para os investidores e de perda de credibilidade para os Estados, com repercussões relevantes sobre o desempenho econômico.

O poder maior do mercado, no entanto, manifesta-se na capacidade de introduzir nas relações humanas, isto é, no tecido fino das relações quotidianas, os critérios, os valores, os métodos que lhe são próprios, sinteticamente indicados como intercâmbio de equivalentes. ${ }^{21} \mathrm{O}$ mercado coloniza o mundo da vida, reduzindo não somente os espaços da gratuidade, tudo calculando em função da conveniência e da utilidade, mas restringindo a própria abertura da razão, que passou a ignorar a busca dos significados, aplicando-se à produção do lucro e do poder. ${ }^{22}$

Para exemplificar, obervamos as consequências não previstas do diagnóstico pré-natal. ${ }^{23}$ Imaginemos uma mulher que faz diagnóstico pré-natal com a intenção de abortar caso o feto não seja saudável. Imaginemos que o feto esteja em ótimas condições de saúde e venha, portanto, a nascer. Provavelmente, aquele filho, chegando aos 15 anos, ficará sabendo que houve uma condição para ser acolhido: a condição de

19 LIPOVETSKY, Gilles. O império do do efêmero. A moda e seu destino nas sociedades moderna. São Paulo: Companhhia das Letras, 1989.

20 PETRINI, João Carlos. Família: abordagem relacional. IN: DONATI, Pierpaolo. Família no século XXI. São Paulo: Paulinas, 2007.

21 A este respeito, veja-se Instrumentum laboris, n. 74.

22 DAp. 50.

23 Cf. AZEVEDO, Eliana. Aborto. In: GARRAFFA, V.; COSTA, S.; IBIAPINA, F. A bioética no século XXI. Brasília: UnB, 2000, p. 85-100. 
ser saudável. O cálculo da conveniência invadiu o espaço do acolhimento, até então, incondicional. Imaginemos, agora, esta mãe idosa e doente. Poderá ela esperar que o filho a acolha e cuide dela, agora sem saúde, já que ela não teria essa disponibilidade para com o filho, quando ele era bebê? Pouco a pouco, cria-se uma mentalidade dominada pelo cálculo das conveniências, que se move no horizonte do mercado, reduzindo-se o espaço da gratuidade. ${ }^{24}$

\section{O processo de banalização}

$\mathrm{O}$ interesse da realidade limita-se aos aspectos que podem ser compreendidos pela razão científica e manipulados pela técnica. $\mathrm{O}$ horizonte do conhecimento reduziu-se ao que interessa ao mercado. O que vale a pena conhecer é o que está ao alcance da razão calculante, é o que pode ser apreendido, analisado, avaliado em sua utilidade, valorizado pelo lucro e pelo poder que proporciona.

É significativo dessa postura o que afirma Dewey numa obra dos anos trinta: "abandonar a busca da realidade, do valor absoluto e imutável pode parecer um sacrifício, mas esta renúncia é condição para empenhar-se em uma vocação mais vital", ${ }^{25}$ a saber, empenhar-se na solução de problemas práticos e técnicos e na procura de valores compartilhados por todos. A ciência moderna declara-se sem competência ou sem interesse em responder a perguntas relevantes para a concreta existência das pessoas. Max Weber no escrito "A ciência como vocação", citando Tolstoi, afirma: "A ciência não tem sentido porque não responde à nossa pergunta, a única pergunta importante para nós: o que devemos fazer e como devemos viver?" E acrescenta: "É inegável que a ciência não dá tal resposta". ${ }^{26} \mathrm{O}$ mesmo Weber afirmava que um médico pode

24 MELINA, L. Corso di bioetica. Casale Monferrato: PIEMME, 1996; SCOLA, A. II mistero nuziale, op. cit.

25 DEWEY, John. The quest for certainty. London: George Allen \& Unwin Ltd., 1930, p. 529.

26 WEBER, Max. Ensaios de sociologia. Rio de Janeiro: Zahar, 1974, p. 169-170. A esse respeito, é interessante a posição de Wittgenstein no Tractatus, quando afirma: "Sentimos que, mesmo que todas as questões científicas possíveis tenham obtido resposta, nossos problemas de vida não terão sido sequer tocados. É certo que não restará, nesse caso, mais nenhuma questão; e a resposta é precisamente essa." WITTGENSTEIN, Ludwig. Tractatus Logico-Philosophicus. Trad. de Luiz Henrique Lopes dos Santos. 3. ed. São Paulo: Edusp, 2001, 6.52. 
prolongar até de maneira significativa a vida de um doente, mas não é capaz de dizer-lhe por que vale a pena viver. ${ }^{27}$

Foi reduzido o espaço reservado à razão na medida em que fica inibido o seu uso para elucidar as questões que mais interessam à pessoa no seu concreto modo de ser e de agir: por que vale a pena viver, qual o significado da vida, do trabalho, do amor, da morte?. Dessa maneira, foram abertos caminhos para que sentimentos e emoções subjetivos pudessem determinar decisões relevantes para a existência, sem que fossem submetidos ao crivo da razão, ampliando-se o território abandonado a formas de irracionalismo.

O abandono do interesse pelo significado da existência conduziu, inevitavelmente, a uma visão banal da realidade e isto abriu as portas para graus antes desconhecidos de violência, especialmente nos centros urbanos. ${ }^{28}$

Desenvolve-se, na cultura dominante, um processo de banalização pelo qual se reduz o significado das coisas. ${ }^{29}$ Lipovetsky afirma: "Todos os 'cumes' se abatem pouco a pouco, arrastados pela vasta operação de neutralização e banalização sociais. Só a esfera privada parece sair vitoriosa desta vaga de apatia. [...] Viver sem ideal e sem fim transcendente tornou-se possível". ${ }^{30}$ A cultura de massa especializou-se em oferecer produtos cuja principal marca é a superficialidade, juntamente com certa retórica da vulgaridade. Impossível não reconhecer, na esteira de Hannah Arendt, uma conexão

27 WEBER, M. op. cit., p. 183. Ironicamente ele questiona: "se a ciência não dá, quem dará a resposta à pergunta: 'Que faremos e como disporemos nossas vidas?' [...]. 'Podemos dizer que somente um profeta ou um salvador podem dar as respostas.' Logo se apressa a dizer que o profeta esperado não existe. Em seguida, ele afirma que quem quiser vencer o desconforto de viver sem respostas às perguntas do porquê e do significado de todas as coisas deve fazer o "sacrifício intelectual", renunciando a usar a razão para poder ter acesso a um profeta ou a um salvador.

28 DAp. 8; 48; 78; 328 (reducionismo antropológico); 409-410.

29 ARENDT, Hannah. Archivio 2, 1950-1954. Milão: Feltrinelli, 2003, p. 25-26: “O aspecto provavelmente mais surpreendente e desconcertante da fuga da realidade [...] é o hábito de tratar os fatos come se fossem meras opiniões [...] Todos os fatos podem ser mudados e todas as mentiras tornadas verdadeiras". E Malraux afirma: "Não há ideal ao qual possamos sacrificar-nos, porque de todos nós conhecemos as mentiras, nós que não sabemos o que é a verdade": MALRAUX, A. La tentation de l'Occident. Paris: Bernard Grasset, 1926, p. 216

30 LIPOVETSKY, Gilles. O império do efêmero. A moda e seu destino nas sociedades moderna. São Paulo: Companhhia das Letras, 1989, p. 48-49. Cf. DAp. $44 ; 51 ; 110 ; 479$. 
entre a cultura da banalidade e o crescimento vertiginoso da violência urbana, especialmente na última década. ${ }^{31}$

\section{A família resiste e adapta-se às mudanças}

Os aspectos "objetivos" da convivência familiar cedem o passo a aspectos "subjetivos", por definição mais instáveis e flutuantes. Verificase uma des-institucionalização da família, no sentido de considerá-la como realidade privada, como se fosse relevante apenas para o percurso existencial dos próprios membros. Prevalece a legitimação da família como grupo social expressivo de afetos, emoções e sentimentos, diminuindo o seu significado público e institucional. ${ }^{32}$

Com o crescimento da sociedade funcionalmente organizada, muitas funções anteriormente reservadas à família passaram a ser desempenhadas por outras agências. A tarefa educativa, a socialização das crianças, os cuidados com a saúde e com o desenvolvimento físico e psíquico, são cada vez mais realizadas pelo Estado ou por agências privadas por causa da menor disponibilidade de tempo dos pais. ${ }^{33}$

Além disso, diante de profissionais dos problemas (psicólogos, pediatras, pedagogos, fonoaudiólogos etc.), a família recua. Até a função mais própria da família, como a de procriar, pode ser desempenhada por laboratórios de fecundação assistida, sem a necessidade de relação sexual entre o homem e a mulher. Esses fatos parecem dar razão a quem se refere à família como uma realidade residual em vias de desaparecimento.

No entanto, a família tem um caráter suprafuncional, adverte Donati. Ela "não existe para satisfazer uma ou algumas funções sociais, mas um leque potencialmente indefinido, enquanto a família é uma relação social plena, ou seja, um fenômeno social total [...] que implica todas as dimensões da existência humana" ${ }^{34}$ Por isso, a família é percebida como realidade fundamental para o delineamento da identidade humana

31 ARENDT, Hannah. Origens do totalitarismo. São Paulo: Companhia das Letras, 1989; IDEM. Eichmenn em Jerusalém: um relato sobre a banalidade do mal. São Paulo: Companhia das Letras, 1999.

32 A este respeito, veja-se Instrumentum laboris, n. 33.

33 A respeito da relação família, educação e Estado, veja-se Instrumentum laboris, n. 136.

34 DONATI, Pierpaolo. Família no século XXI. São Paulo, Paulinas, 2007, p. 4. 
e social, tanto é verdade que "o símbolo da família é dos mais fortes, estáveis e relevantes no tempo da vida social, desde o início da história humana até hoje", afirma Donati. ${ }^{35}$

Aumentam as separações e os divórcios, os jovens casam mais tarde em comparação a duas décadas atrás, diminui também significativamente o número dos casamentos, aumenta o número de famílias reconstituídas, as uniões de fato, as famílias monoparentais e as chefiadas por mulheres. ${ }^{36}$ As mudanças são de tal magnitude ${ }^{37}$ que influenciam a família a ponto que parece desaparecer. É dos anos 70 o livro de Cooper, que anunciava "a morte da família". ${ }^{38}$ É interessante, também, a afirmação de Giddens quando disse que a família emerge como "o local para as lutas entre a tradição e a modernidade, mas também uma metáfora para elas". 39

Reagindo aos condicionamentos externos ${ }^{40}$ e, ao mesmo tempo, adaptando-se a eles, a família encontra novas formas de estruturação que, de alguma maneira, a reconstituem. ${ }^{41}$ Sinal disso são as novas famílias, isto é, as famílias que pertencem à Pastoral Familiar ou a movimentos católicos e a novas comunidades que absorvem os valores modernos da igualdade entre os sexos, do maior diálogo entre pais e filhos, renunciando a posturas autoritárias, mas preservam a dedicação à família até o sacrifício, valorizam a fidelidade conjugal e o conjunto de valores próprios da Igreja.

Nesse contexto (anos 70/80) compreende-se a grandeza de São João Paulo II, o Papa da Família. Não somente as catequeses das quartas

35 Ibidem. Cf. DAp. 114-119. Veja-se também Instrumentum laboris, n.32.

36 BERQUÓ, Elza. Arranjos Familiares no Brasil: uma visão demográfica. In: SCHAWRCZ, Lilia M. Org. História da vida privada no Brasil, v.4. São Paulo: Companhia das Letras, 1998, p. 411-438.

37 GOLDANI, A. M. As Famílias brasileiras: mudanças e perspectivas. In: Caderno de Pesquisa. São Paulo, n. 91, p. 7-22, nov. 1994. Cf. DAp. 437j e 437k.

38 COOPER, David. A morte da família. São Paulo: Martins Fontes, 1994.

39 GIDDENS, Anthony. Mundo em descontrole. O que a globalização está fazendo de nós. Rio de Janeiro: Record, 2000, p. 63.

40 SARTI, Cynthia. Algumas questões sobre família e políticas sociais. In: JACQUE, C.; COSTA, L. (Orgs.). Família em mudança. São Paulo: Companhia Ilimitada, 2004, pp. 193-213.

41 DONATI, Pierpaolo. Manuale di sociologia della famiglia. Bari: Laterza, 1998; DONATI, Pierpaolo e SCABINI, Eugenia (Orgs.). Nuovo lessico familiare. Milão: Vita e Pensiero, 1995. 
feiras foram de fundamental importância, ${ }^{42}$ mas a publicação da Exortação Apostólica Familiaris Consortio, ${ }^{43}$ a criação do Pontifício Instituto João Paulo II para Estudos sobre Matrimônio e Família, ${ }^{44}$ presente em todos os continentes, e a criação dos Encontros Mundiais das Famílias constituíram gestos de grande significado. Assim, o Papa falava com a Igreja inteira (a exortação), com os intelectuais do mundo (o Instituto) e com a mídia (os encontros mundiais).

A partir dos anos 80, inicialmente na Europa e nos Estados Unidos e, em seguida, em todo o mundo, multiplicaram-se estudos sobre a família, redescobrindo a importância da família, considerada funcional ao bem-estar das pessoas, à socialização e educação das novas gerações, à paz na sociedade, para diminuir as despesas públicas.

São identificados, em seguida, alguns desafios que a família deve enfrentar e os passos que uma Pastoral Familiar "intensa e vigorosa" pode sugerir para não perder a capacidade crítica diante das circunstâncias e para exercer seu protagonismo e sua criatividade.

\section{Os desafios e os passos para consolidar a família cristã}

No nosso tempo, a família deve enfrentar muitos desafios, alguns dos quais são tão relevantes que podem alterar suas características essenciais, até comprometer a sua existência. Alguns desafios são de caráter social, isto é, procedem da organização que a sociedade vem assumindo nos últimos anos, outros são de caráter antropológico-cultural.

\section{Desafios de caráter social}

Primeiro desafio: $\mathrm{O}$ mundo do trabalho absorve sempre mais as energias dos trabalhadores, alonga-se a jornada de trabalho, inclusive por causa da difícil mobilidade urbana. A necessidade que marido e mulher trabalhem fora de casa para cobrir as despesas cria circuns-

\footnotetext{
42 JOÃO PAULO II. Homem e mulher o criou: catequeses sobre o amor humano. Bauru: Edusc, 2005.

43 JOÃO PAULO II. A missão da família cristã no mundo de hoje. Exortação Apostólica Familiaris Consortio. São Paulo: Paulinas, 1981.

44 Citado também no Instrumentum laboris, n. 18.
} 
tâncias que tornam mais frágeis as relações familiares e põem em risco a permanência do vínculo. ${ }^{45} \mathrm{~A}$ redução do tempo para conviver empobrece a qualidade das relações. Ulrich Beck escrevia nos anos 80 que na sociedade capitalista plenamente realizada não há lugar para a família, não há lugar para os filhos ${ }^{46} \mathrm{O}$ casal que não enfrenta com coragem e criatividade essas situações, corre o perigo de não encontrar mais o tempo necessário para cultivar relações significativas entre si e com os filhos.

Primeiro passo: É necessário favorecer a organização de associações de famílias que possam estabelecer um diálogo nacional com o objetivo de elaborar políticas familiares de modo que a lógica do capital não domine a família a ponto de desfigurá-la.

\section{Desafios de caráter cultural e antropológico}

Uma pesquisa realizada pelo Instituto da Família de Salvador em duas grandes cidades do Brasil revelou que as famílias brasileiras, em grande medida migrantes de regiões rurais, vivem uma ambivalência de valores, muitas vezes, em contradição entre si. De um lado, estão vivos os valores recebidos no ambiente familiar e que valorizam a fidelidade conjugal, a disponibilidade ao sacrifício pessoal para o bem do grupo familiar, a dedicação gratuita para construir o bem da família e de cada membro, a disponibilidade ao perdão. De outro lado, estão presentes os valores que são exaltados pelos meios de comunicação e que valorizam a autonomia individual, a emancipação e o empowerment da mulher, a busca pela realização pessoal, mesmo com sacrifício da convivência em família.

Esta pesquisa nos sugeriu de ajudar as famílias a adquirir uma capacidade crítica que torne possível escolher com liberdade o que efetivamente a pessoa quer, dando-se conta das implicações de cada passo dado. Identificamos alguns desafios que devem ser enfrentados e passos concretos para superá-los. Para tomar consciência dos desafios e dar os passos é necessário que as famílias não vivam isoladas, mas constituam pequenas comunidades, ${ }^{47}$ onde seja possível compartilhar problemas,

45 Citado também no Instrumentum laboris, n. 18.

46 BECK, Ulrich. I rischi della libertà. L'individuo nell'epoca della globalizzazione. Bolonha: II Mulino, 2000.

47 Veja-se Instrumentum laboris, nn. 48; 85. 
ajudando-se a compreender situações complexas, cultivando a amizade, mantendo vivo o olhar crítico. ${ }^{48}$

Segundo desafio: O ser humano existe sempre e somente em relação. Não se faz, é feito por outros, ou melhor, por Outro. Todavia, difunde-se uma mentalidade individualista que cultiva a ilusão da total autonomia. Um trecho dos "Manuscritos económicos filosóficos de 44" de Karl Marx afirma exactamente o contrario, isto é, que o sujeito humano cria-se a si mesmo, é o autor de sua própria existência, num processo de autogênese através do trabalho. ${ }^{49}$

Segundo passo: Os membros da família cristã podem ser ajudados a cultivar a consciência de uma pertença que os constitui e de uma dependência que os ajuda a crescer, até o reconhecimento do Mistério do qual tudo depende. O sacramento do Matrimônio configura essa pertença que é alimentada pela Eucaristia e iluminada pela Palavra e se concretiza através da inserção da família numa concreta comunidade cristã: oração em família, missa dominical e vida na comunidade cristã.

Terceiro desafio: Na sociedade moderna cada pessoa vive uma multiplicidade de interesses. O perigo é considerar a família um dos interesses e não o principal.

Terceiro passo: As pessoas podem ser educadas a viver a família como vocação, que unifica e cria convergência entre os diversos aspectos da vida. Dessa maneira, ela é vivida como a construção mais importante à qual um homerm e uma mulher dedicam o melhor de seus recursos ${ }^{50}$ Daqui vem a indicação de reservar tempo para conviver, dialogar e cuidar.

48 DAp. 372, sobre comunidades de famílias.

49 MARX, Karl. Manoscritti economici-filosofici del '44. Trad. It. De N. Bobbio, Turim: Einaudi, 1968, pp. 122-125. "Um ser se considera independente somente quando é dono de si, e é dono de si somente quando é devedor a si mesmo da própria existência. Um homem que vive da graça alheia considera-se como um ser dependente. Mas eu vivo completamente da graça alheia quando sou devedor para com o outro, não somente do sustento de minha vida, mas também quando este, além disso, criou a minha vida, é a fonte da minha vida; e a minha vida tem necessariamente um tal fundamento fora de si, quando não é a minha própria criação. Sendo que para o homem socialista toda a assim chamada história do mundo nada mais é senão a geração do homem por meio do trabalho humano, ele tem a prova evidente, irresistível, do seu nascimento através de si mesmo, do processo de sua origem".

Veja-se Instrumentum laboris, n. 31. 
No horizonte da vocação pode-se compreender a indissolubilidade do Matrimônio como resposta ao problema da desintegração (implosão) do tempo. As feridas do divórcio deixam grandes sofrimentos porque cancela o passado e torna incerto o futuro. A doutrina da Igreja sobre o Matrimônio indissolúvel é uma grande misericórdia social porque valoriza o passado e promove a realização da promessa de bem para o futuro.

Quarto desafio: Cada pessoa desenvolve funções e entra em relação com os outros por aspectos limitados, ligados à especificidade da função. As relações, nesse contexto, referem-se a aspectos parciais da vida e tendem a ser fragmentadas. Pelo contrário, a família é o espaço onde a pessoa entra com a totalidade do seu ser: sentimentos, afetos, valores, interesses, ideais, preocupações, trabalho, religião, sucessos, doença etc.

Quarto passo: A família cristã pode ser educada a cultivar relações que tenham o caráter da totalidade e a ter atitude de vigilância.

Quinto desafio: Na atual cultura, prevalece a lógica do mercado, onde o que interessa é a troca de equivalentes. Tende-se a calcular a vantagem, a conveniência, a utilidade de cada aspecto da vida social. Esta mentalidade contagia facilmente as relações familiares a ponto de usar frequentemente uma linguagem bancária: "Investi tanto nesse relacionamento, veja agora qual é o retorno!" Sentir-se devedor para o outro abre à dedicação atenta. Sentir-se credor do outro abre para a cobrança e o ressentimento, sinaliza que a mentalidade mercantil está entrando no relacionamento.

Quinto Passo: O homem e a mulher realizam-se fazendo dom de si, sincero e total, ao outro. ${ }^{51}$ Trocar dons é a arte de cultivar relacionamentos. Na família domina a dinâmica do dom sincero de si (GS 24) até o sacrifício para o bem do outro. O dom é uma ponte lançada em direção ao coração de quem o recebe, tem um significado simbólico, contém um excedente de significado que ultrapassa de longe o seu valor comercial. ${ }^{52}$ Não pode faltar a atenção a reconhecer quando a lógica do mercado se introduz nas relações para fazer as oportunas correções.

51 Veja-se Instrumentum laboris, n. 33.

52 Para aprofundar este tema ver MAUSS, Marcel. Ensaio sobre a dádiva. Lisboa: Edições 70, 2001, e seus comentadores, especialmente GODBOUT, Jacques. O espírito da dádiva. Com Alain Caillé. Rio de Janeiro: FGV, 1999. 
Sexto desafio: A família é constituída por relações de plena reciprocidade entre os sexos e entre as gerações. Essa reciprocidade tem uma base afetiva (subjetiva) e uma dimensão estrutural (objetiva) que constituem o vínculo próprio da família como vivência do amor fundada no matrimônio. A busca individualista de satisfações empobrece a reciprocidade no casal, planeja a esterilidade e diminui a responsabilidade entre as gerações.

Sexto passo: A família pode ser ajudada a viver a reciprocidade de afetos e de responsabilidade com abertura à geração de filhos e à sua educação. Aqui está a gênese da cooperação e da solidariedade familiar, para dentro e para fora. Alguém se importa comigo. Sua existência me importa. A abertura para viver a paternidade e a maternidade, para cuidar das crianças e dos idosos é fonte de crescimento humano e não deixa decair a família numa reciprocidade contábil e formal.

Sétimo desafio. A cultura que exalta o individualismo reduz a solidariedade para com o parentesco e com outros. A autonomia é o fruto do individualismo e do utilitarismo e tende a reduzir o significado das relações familiares até a ruptura dos vínculos. Viver sem prestar conta a ninguém das próprias ações, seguindo o sonho da própria realização ignora possíveis sofrimentos que se podem causar.

Sétimo passo. As pessoas podem ser ajudadas a viver relações familiares caracterizadas pelo "nós" (Igreja Doméstica). A identidade mais profunda da família é a comunhão que gera o "nós". O cônjuge e os filhos estão sempre presentes no diálogo e nos encontros que cada membro desenvolve fora de casa e nas escolhas que é chamado a fazer. Essa família cultiva a hospitalidade, que pode crescer até receber a guarda de uma criança ou a adoção. A solidariedade começa com a oração pelas pessoas em necessidade e se concretiza com gestos de acolhida e caridade pensados e realizados em conjunto. ${ }^{53}$

\section{Para concluir}

O amor conjugal cultivado segundo a imagem do amor divino, como dom sincero de si à imitação da Santíssima Trindade dá vida a

53 Veja-se ibidem, nn. 33; 48. 
uma experiência humana vibrante, a uma comunhão apaixonada, a uma vida intensa e admirável.

O testemunho de uma humanidade redimida, de pessoas realizadas e felizes na família cristã poderá vencer o vazio de humanidade que se percebe no quotidiano e que é alimentado pela ideologia do relativismo e do individualismo. Assim, nasce a família missionária, capaz de comunicar aos outros a alegria, a beleza e a paz de que faz experiência. Uma realidade assim pode existir somente como fruto de uma educação que oferece aos membros da família as razões para decidir livremente suas escolhas de vida e o reconhecimento da graça que é Jesus Cristo presente.

E-mail do autor:

giancarlo.petrini@uol.com.br 